\title{
Predicting primary postoperative pulmonary complications in patients undergoing minimally invasive surgery for colorectal cancer
}

\author{
Mohamed A. Abd El Aziz ${ }^{1} \cdot$ William R. Perry $^{1} \cdot$ Fabian Grass $^{1} \cdot$ Kellie L. Mathis ${ }^{1} \cdot$ David W. Larson $^{1} \cdot$ Jay Mandrekar $^{2}$. \\ Kevin T. Behm ${ }^{1}$
}

Received: 9 August 2020 / Accepted: 17 September 2020 / Published online: 1 October 2020

(C) Italian Society of Surgery (SIC) 2020

\begin{abstract}
Objective To determine the risk factors for developing primary postoperative pulmonary complications (PPC) in patients undergoing minimally invasive colorectal surgery (MIS) for the treatment of cancer and to identify the potential indicators for more extensive preoperative evaluation.

Materials and methods The ACS-NSQIP ${ }^{\circledR}$ database was interrogated to capture patients who had elective colon or rectal cancer and underwent MIS between 2012 and 2017. Patients who had primary PPC including pneumonia, unplanned intubation and/or failure to wean from mechanical ventilation for $>48$ h were compared to patients without PPC. Significant risk factors for PPC were retained to build a predictive risk model through logistic regression analysis. The model was then internally validated using 2018 data.

Results Of 50,150 patients identified, 637 (1.3\%) had PPC. The final risk prediction model included six variables: history of chronic obstructive pulmonary disease, age, smoking status, functional health status, pre-operative congestive heart failure, and American Society of Anesthesiology class $\geq 3$. The model achieved good calibration (Hosmer-Lemeshow goodness-of-fit test, $p=0.614$ ) and discrimination ( $c$ statistics $=0.757$ ). Internal validation achieved similar discrimination ( $c$ statistics $=0.798)$.

Conclusion Primary postoperative pulmonary complications affected $1.3 \%$ of patients undergoing MIS for colon or rectal cancer. The novel predictive risk score showed good discrimination and may help to identify patients who may benefit from perioperative optimization.
\end{abstract}

Keywords Colorectal surgery $\cdot$ Minimally invasive surgery $\cdot$ Colorectal cancer $\cdot$ Respiratory complications $\cdot$ Pneumonia Unplanned intubation · Failure to wean from mechanical ventilation

\section{Introduction}

Postoperative pulmonary complications (PPC) are infrequent but critically important after colorectal surgery [1]. Approximately $20 \%$ of patients who have PPC will die within 30 days, in comparison to $0.2-3 \%$ who do not develop PPC [2]. Affected patients also have increased length of stay and associated cost of care $[3,4]$.

Kevin T. Behm

behm.kevin@mayo.edu

1 Division of Colon and Rectal Surgery, Department of Surgery, Mayo Clinic, 200 First St. Southwest, Rochester, MN 55905, USA

2 Department of Health Sciences Research, Mayo Clinic, Rochester, MN, USA
The impact of risk factors on postoperative respiratory function and complications has yet to be defined in the setting of minimally invasive surgery (MIS). The use of carbon dioxide pneumoperitoneum with laparoscopy reduces lung compliance and functional residual capacity, which in turn increases the risk of hypoxemia [5, 6]. As such, open techniques have historically been recommended for patients deemed high-risk.

Despite these concerns, several studies have reported that MIS does not increase PPC [2, 7]. Furthermore, MIS is associated with decreased pain, accelerated functional recovery, and shorter length of stay when compared to open surgery [8-10]. Laparoscopic colonic surgery is linked to a lower risk of postoperative respiratory complications, decreased postoperative morbidity, and a shorter length of stay compared with open colonic surgery [11-15]. 
To date, the identification of factors associated with PPC within a MIS framework has yet to be defined. This study aimed to document characteristics of patients who had PPC following minimally invasive colorectal cancer surgery. A tool to predict PPC was then built from this information.

\section{Methods}

\section{Data source}

Data were obtained from the American College of Surgeons National Surgical Quality Improvement Program (ACSNSQIP) database. ACS-NSQIP program is a nationally validated, and outcome-based program which was developed to measure and improve the quality of surgical care. Patients' data are collected by trained clinical abstractors based on a predesigned data extraction sheet. Data from all participating institutions are collected and $20 \%$ of the patients are retained in the final files.

\section{Cohort}

All patients who had minimally invasive colon or rectal surgery between January 2012 and December 2017 were identified using the Current Procedure Terminology (CPT) codes: 44,204, 44,205, 44,206, 44,207, 44,208, 44,210, 44,211, $44,212,45,395$, and 45,397. Patients with colon or rectal cancer were identified using the International Classification of Diseases (ICD) codes: ICD-9-CM 153.x, 230.3, and 230.4; and ICD-10-CM D01.0, D01.1, D01.2, C18.x, C19, and C20. Patients were excluded if they had emergent or non-elective (urgent) surgery, a concurrent operation under a different attending or an American Society of Anesthesiology Class (ASA) V. Patients who had major complications before the onset of respiratory complications were also excluded. These included cardiac arrest requiring resuscitation, myocardial infarction, pulmonary embolism, septic shock, reoperation, and organ space infection due to leak.

\section{Outcomes}

Our primary outcome was development of primary PPC defined as pneumonia, unplanned reintubation, or failure to wean from the ventilator within the participant data use file (PUF). Primary PPC was defined as a pulmonary complication that preceded another known major complication. Pneumonia is only reported in the presence of radiological features in combination with signs, symptoms, or laboratory confirmation. Unplanned reintubation was defined as unintended endotracheal intubation and mechanical ventilation after extubation. Failure to wean was ascribed if mechanical ventilation was required for a total cumulative time of more than 48 h. Our secondary outcome was a 30-day mortality rate.

\section{Statistical analysis}

Data were reported as frequency and proportions for categorical variables and median (interquartile range) for continuous variables. Demographics and pre-operative characteristics were compared between patients who had PPC and patients who did not have PPC using the Chi-Square test or Fisher's exact test for categorical variables and Mann-Whitney $U$ test for continuous variables.

A multivariable logistic regression with stepwise variable selection was then used to build a prediction model for the primary outcome (PPC). Independent risk factors associated with a PPC $(p<0.1)$ in the univariate analysis were entered in the initial model. With a backward elimination procedure, only significant risk factors $(p<0.05)$ were kept. Then, a forward stepwise selection method was utilized which achieved the same model. Once a stable model was built, all eliminated variables were rechecked none of which had a significant effect on the model. Odds ratios (OR) with $95 \%$ confidence intervals $(\mathrm{CI})$ were used to measure the magnitude of the association.

The proposed prediction model was then internally validated using the PUF 2018. Hosmer Lemeshow goodness-offit test was used to test the calibration of the proposed score in both datasets. A $c$ statistics obtained from the receiver operating characteristic (ROC) curve was then used to assess the discriminative ability of the model in both datasets. The statistical analysis was performed using the Statistical Package for Social Sciences (SPSS, Version 25; SPSS, Inc., Armonk, NY, USA). In our analysis, an alpha level of less than 0.05 was considered statistically significant.

\section{Results}

Some 50,150 patients from the ACS NQIP program were included from 2012 to 2017 . Of these patients, $420(0.8 \%)$ developed pneumonia, $260(0.5 \%)$ developed unplanned reintubation, and $57(0.1 \%)$ patients needed mechanical ventilation for more than $48 \mathrm{~h}$. Collectively, $637(1.3 \%)$ developed PPC. Patients who developed respiratory complications were more likely to be male, older, and with more co-morbidities as outlined in Table 1. Patients who had a PCC had a higher 30-day mortality rate compared to patients who did not have a PCC $(17.5 \%$ vs $0.2 \% ; p<0.0001)$.

Of all the examined variables, the final risk assessment model for prediction of PCC development included six risk factors: a history of chronic obstructive pulmonary disease, age, smoking status, functional health status, 
Table 1 Baseline and surgical characteristics

\begin{tabular}{|c|c|c|c|c|}
\hline & \multicolumn{3}{|c|}{ Respiratory complications } & \multirow[t]{2}{*}{$p$ value } \\
\hline & Yes & No & Total & \\
\hline Number of patients & 637 & 49,513 & 50,150 & \\
\hline Gender & & & & $<0.0001$ \\
\hline Female & $256(40.2 \%)$ & $23,774(48.0 \%)$ & $24,030(47.9 \%)$ & \\
\hline Race & & & & $<0.0001$ \\
\hline White & $445(69.9 \%)$ & $34,797(70.3 \%)$ & $35,242(70.3 \%)$ & \\
\hline African American & $55(8.6 \%)$ & $4215(8.5 \%)$ & $4270(8.5 \%)$ & \\
\hline Asian & $10(1.6 \%)$ & $2541(5.1 \%)$ & $2551(5.1 \%)$ & \\
\hline American Indian or Alaska Native & $3(0.5 \%)$ & $185(0.4 \%)$ & $188(0.4 \%)$ & \\
\hline Native Hawaiian or Pacific Islander & 0 & $170(0.3 \%)$ & $170(0.3 \%)$ & \\
\hline Unknown/not reported & $124(19.5 \%)$ & $7605(15.4 \%)$ & $7729(15.4 \%)$ & \\
\hline Hispanic & & & & $<0.0001$ \\
\hline Yes & $15(2.4 \%)$ & $2410(4.9 \%)$ & $2425(4.8 \%)$ & \\
\hline No & $499(78.3 \%)$ & $40,262(81.3 \%)$ & $40,761(81.3 \%)$ & \\
\hline Unknown & $123(19.3 \%)$ & $6841(13.8 \%)$ & $6964(13.9 \%)$ & \\
\hline BMI, $\mathrm{kg} / \mathrm{m}^{2}$ & & & & 0.146 \\
\hline Normal (BMI 18.5-25) & $201(31.6 \%)$ & $14,287(28.9 \%)$ & $14,488(28.9 \%)$ & \\
\hline Under weight $(\mathrm{BMI}<18.5)$ & $13(2.0 \%)$ & $866(1.7 \%)$ & $879(1.8 \%)$ & \\
\hline Over weight (BMI 25-30) & $202(31.7 \%)$ & $17,388(35.1 \%)$ & $17,590(35.1 \%)$ & \\
\hline Class I obesity (BMI 30-35) & $119(18.7 \%)$ & $10,078(20.4 \%)$ & $10,197(20.3 \%)$ & \\
\hline Class II obesity (35-40) & $60(9.4 \%)$ & $4134(8.3 \%)$ & $4194(8.4 \%)$ & \\
\hline Class III obesity $(\mathrm{BMI}>40)$ & $36(5.7 \%)$ & $2541(5.1 \%)$ & $2577(5.1 \%)$ & \\
\hline Missing & $6(0.9 \%)$ & $219(0.4 \%)$ & $225(0.4 \%)$ & \\
\hline Age, years & & & & $<0.0001$ \\
\hline$<50$ & $24(3.8 \%)$ & $5795(11.7 \%)$ & $5819(11.6 \%)$ & \\
\hline $50-59$ & $47(7.4 \%)$ & $10,960(22.1 \%)$ & $11,007(21.9 \%)$ & \\
\hline $60-69$ & $122(19.2 \%)$ & $13,518(27.3 \%)$ & $13,640(27.2 \%)$ & \\
\hline $70-79$ & $225(35.3 \%)$ & $12,004(24.2 \%)$ & $12,229(24.4 \%)$ & \\
\hline $80-89$ & $187(29.4 \%)$ & $6429(13.0 \%)$ & $6616(13.2 \%)$ & \\
\hline$\geq 90$ & $32(5.0 \%)$ & $806(1.6 \%)$ & $838(1.7 \%)$ & \\
\hline DM & & & & $<0.0001$ \\
\hline No diabetes & $498(78.2 \%)$ & $40,510(81.8 \%)$ & $41,008(81.8 \%)$ & \\
\hline Insulin dependent & $59(9.3 \%)$ & $2631(5.3 \%)$ & $2690(5.4 \%)$ & \\
\hline Non-insulin dependent & $80(12.6 \%)$ & $6372(12.9 \%)$ & $6452(12.9 \%)$ & \\
\hline Current smoker & $112(17.6 \%)$ & $6099(12.3 \%)$ & $6211(12.4 \%)$ & $<0.0001$ \\
\hline COPD & $130(20.4 \%)$ & $2105(4.3 \%)$ & $2235(4.5 \%)$ & $<0.0001$ \\
\hline Dyspnea & & & & $<0.0001$ \\
\hline No & $510(80.1 \%)$ & $46,147(93.2 \%)$ & $46,657(93.0 \%)$ & \\
\hline Yes, at rest & $13(2.0 \%)$ & $156(0.3 \%)$ & $169(0.3 \%)$ & \\
\hline Yes, at moderate exertion & $114(17.9 \%)$ & $3210(6.5 \%)$ & $3324(6.6 \%)$ & \\
\hline Functional status & & & & $<0.0001$ \\
\hline Independent & $587(93.3 \%)$ & $48,627(98.6 \%)$ & $49,214(98.1 \%)$ & \\
\hline Partially dependent & $37(5.9 \%)$ & $623(1.3 \%)$ & $660(1.3 \%)$ & \\
\hline Totally dependent & $5(0.8 \%)$ & $68(0.1 \%)$ & $73(0.1 \%)$ & \\
\hline Ventilator dependent & $2(0.3 \%)$ & $3(0.0 \%)$ & $5(0.0 \%)$ & $<0.0001$ \\
\hline Ascites & $3(0.5 \%)$ & $60(0.1 \%)$ & $63(0.1 \%)$ & 0.013 \\
\hline $\mathrm{CHF}$ & $27(4.2 \%)$ & $315(0.6 \%)$ & $342(0.7 \%)$ & $<0.0001$ \\
\hline Antihypertensive therapy & $457(71.7 \%)$ & $25,560(51.6 \%)$ & $26,017(51.9 \%)$ & $<0.0001$ \\
\hline Hemodialysis & $4(0.6 \%)$ & $183(0.4 \%)$ & $187(0.4 \%)$ & 0.288 \\
\hline Disseminated cancer & $52(8.2 \%)$ & $2706(5.5 \%)$ & $2758(5.5 \%)$ & 0.003 \\
\hline
\end{tabular}


Table 1 (continued)

\begin{tabular}{|c|c|c|c|c|}
\hline & \multicolumn{3}{|c|}{ Respiratory complications } & \multirow[t]{2}{*}{$p$ value } \\
\hline & Yes & No & Total & \\
\hline Open wound/wound infection & $8(1.3 \%)$ & $181(0.4 \%)$ & $189(0.4 \%)$ & $<0.0001$ \\
\hline Steroid use for chronic condition & $37(5.8 \%)$ & $1300(2.6 \%)$ & $1337(2.7 \%)$ & $<0.0001$ \\
\hline$>10 \%$ weight loss in the last 6 months & $27(4.2 \%)$ & $1495(3.0 \%)$ & $1522(3.0 \%)$ & 0.075 \\
\hline Bleeding disorder & $28(4.4 \%)$ & $1121(2.3 \%)$ & $1149(2.3 \%)$ & $<0.0001$ \\
\hline $\begin{array}{l}\text { Transfusion of } \geq 1 \text { unit of pRBCs } 72 \mathrm{~h} \\
\text { prior to surgery }\end{array}$ & $18(2.8 \%)$ & $331(0.7 \%)$ & $349(0.7 \%)$ & $<0.0001$ \\
\hline ASA class & & & & $<0.0001$ \\
\hline I and II & $119(18.7 \%)$ & $22,585(45.7 \%)$ & $22,704(45.3 \%)$ & \\
\hline III and IV & $518(81.3 \%)$ & $26,870(54.3 \%)$ & $27,388(54.7 \%)$ & \\
\hline \multicolumn{5}{|l|}{ Preoperative laboratories; median (IQR) } \\
\hline Albumin, g/dL & $3.8(3.4-4.1)$ & $4(3.7-4.3)$ & $4(3.7-4.3)$ & $<0.0001$ \\
\hline Hematocrite, \% & $35.8(31.5-40.5)$ & $38.5(34.2-41.9)$ & $38.7(34.5-42)$ & $<0.0001$ \\
\hline Platelets, $1000 / \mu \mathrm{L}$ & $245(195-320)$ & $249(204-306)$ & $248(204-304)$ & $<0.0001$ \\
\hline Operation time & $162(117-222)$ & $168(122-234)$ & $165(120-229)$ & 0.210 \\
\hline 30-Day mortality & $94(14.8 \%)$ & $118(0.2 \%)$ & $212(0.4 \%)$ & $<0.0001$ \\
\hline
\end{tabular}

$C O P D$ chronic obstructive pulmonary disease, $B M I$ Body Mass Index, $D M$ diabetes mellitus, $C H F$ congestive heart failure, $p R B C s$ packed red blood cells, ASA American Society of Anesthesiologist

congestive heart failure within 30 days prior to surgery, and ASA class (Table 2).

The multiple logistic regression equation was as follows:

$L=-5.932+(1.157 \times$ presence of COPD $)+(-0.109 \times$ age: 50 to 59$)+(0.469 \times$ age: 60 to 69$)+(1.112 \times$ age: 70 to $79)+(1.484 \times$ age: 80 to 89$)+(1.789 \times$ age $\geq 90)+(0.578$ $\times$ current smoker $)+(0.857 \times$ functional status partially dependent $)+(1.227 \times$ functional status totally dependent $)+(1.015 \times$ CHF $)+(0.743 \times$ ASA III_IV $)$.

The estimated probability of 30-day PPC was calculated using the following formula:

Estimated probability of composite adverse event $=\operatorname{EXP}[L] /(1 p$ EXP $[L])$.

As shown in Table 3, the model demonstrated good calibration (Hosmer-Lemeshow goodness-of-fit test, $\chi^{2}=6.297$,
Table 2 Predictors of postoperative respiratory complications: results of multivariable logistic regression analysis in PUF 2012-2017

\begin{tabular}{lccc}
\hline & $\beta$-coefficient & OR & 95\% CI \\
\hline History of COPD & 1.157 & 3.179 & $(2.575-3.925)$ \\
Age; years & & & \\
$\quad<50$ (reference) & & & \\
$50-59$ & 0.109 & 0.897 & $(0.547-1.470)$ \\
$60-69$ & 0.469 & 1.599 & $(1.027-2.490)$ \\
$70-79$ & 1.112 & 3.041 & $(1.980-4.672)$ \\
$80-89$ & 1.484 & 4.410 & $(2.844-6.840)$ \\
$\geq 90$ & 1.789 & 5.981 & $(3.452-10.365)$ \\
Current smoker within one year & 0.578 & 1.783 & $(1.429-2.225)$ \\
Functional health status prior to surgery & & & \\
Independent (reference) & & & $(1.653-3.358)$ \\
Partially dependent & 0.857 & 2.356 & $(1.327-8.770)$ \\
Totally dependent & 1.227 & 3.411 & $(1.815-4.192)$ \\
CHF within 30 days prior to surgery & 1.015 & 2.758 & $(1.702-2.596)$ \\
ASA classification & & & \\
(III and IV) vs (I and II) & 0.743 & 2.102 & \\
Constant & -5.932 & & \\
\hline
\end{tabular}

PUF participant user files, $C O P D$ chronic obstructive pulmonary disease, $D M$ diabetes mellitus, $C H F$ congestive heart failure, ASA American Society of Anesthesiologist, 
Table 3 Calibration and discriminatory statistics for the regression model

\begin{tabular}{lllll}
\hline & $c$ statistic & $\begin{array}{l}\text { Standard } \\
\text { error }^{\mathrm{a}}\end{array}$ & $\begin{array}{l}\text { Asymptotic } \\
\text { 95\% confi- } \\
\text { dence interval }\end{array}$ & $p$ value \\
\hline $\begin{array}{l}\text { PUF (2012- } \\
\text { 2017): }\end{array}$ & 0.757 & 0.010 & $0.738-0.776$ & $<0.0001$ \\
$\begin{array}{l}\text { model } \\
\text { development } \\
\text { data set }\end{array}$ & & & & \\
$\begin{array}{l}\text { PUF 2018: } \\
\text { model }\end{array}$ & 0.798 & 0.017 & $0.765-0.832$ & $<0.0001$ \\
$\begin{array}{l}\text { validation } \\
\text { data set }\end{array}$ & & & & \\
\hline
\end{tabular}

PUF participant user files

${ }^{\mathrm{a}}$ Under the nonparametric assumption

$p$ value $=0.614)$ and discrimination $(c$ statistic $=0.757)$. The generated model based on 2012-2017 ACS-NSQIP ${ }^{\circledR}$ was then internally validated using the 2018 ACS-NSQIP ${ }^{\circledR}$ data which showed relatively similar performance ( $c$ statistic $=0.798)($ Fig. 1).

The performance of the risk prediction model at different cut-off points is shown in Table 4. Using the predicted probability of $\geq 1.96 \%$ as a cut-off value, the model achieved a specificity of $83.7 \%$ for detecting the PPC. In other words, those with a predicted probability of $\geq 1.96 \%$ were at higher risk of having pulmonary complications.

\section{Discussion}

This study documents the characteristics of patients who had primary PPC after minimally invasive surgery for colorectal cancer while excluding major postoperative complications that occurred before the onset of PCC. Other major postoperative complications might be a potential cause for the PPC, and as such were excluded from the analysis to provide a precise hands-on predictive tool to identify these patients based on pre-operative data.

Our study population rate of PPC (1.3\%) fell below the $2 \%$ median incidence of PPC after MIS identified in a 2015 systematic review of randomized controlled trials that compared laparoscopic versus open surgery for colorectal cancer [16]. Some studies included in the systematic review had more broadly encompassing definitions of PPC in comparison to our more narrow definition. The difference may also represent a healthy selection bias given high-risk patients who underwent open surgery were ultimately excluded from our analysis.

Males had a higher preponderance of PPC (59.8\%), as did the elderly, those with diabetes, and those with more comorbidities as seen in patients with an ASA score of 3 or more.
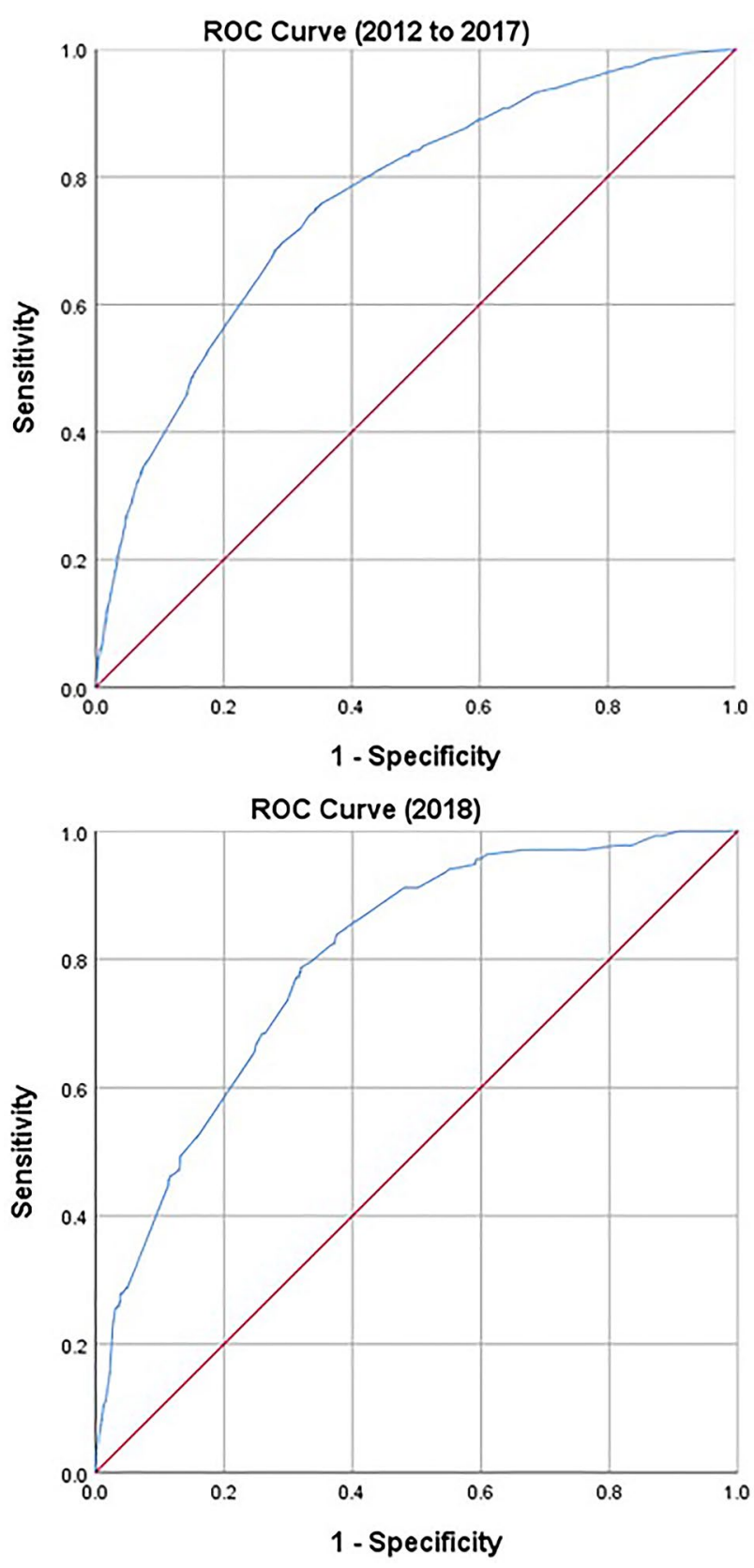

Fig. 1 receiver operating characteristic curves

Table 4 Performance of risk calculator at various cut-points

\begin{tabular}{llll}
\hline Cut-point & Sensitivity (\%) & Specificity (\%) & Youden's $J^{\text {a }}$ \\
\hline$\geq 0.556$ & 88 & 42 & 30 \\
$\geq 0.934$ & 75.7 & 64.4 & 40.1 \\
$\geq 1.62$ & 67.2 & 71.2 & 38.4 \\
$\geq 1.96$ & 50.2 & 83.7 & 33.9 \\
$\geq 2.45$ & 34.3 & 92.3 & 34 \\
\hline
\end{tabular}

ayouden's $J$ test calculated by the following formula: (sensitivity + specificity -1 ) to identify the best cut-off point 
Expected risk factors and markers of poor respiratory function, such as smoking, dyspnea, and impaired functional status, also increased the risk of PPC. In contrast to former evidence, there was no significant association with BMI [17]. This may speak to the benefit of MIS for obese patients: a smaller incision often results in less pain which allows more optimal respiratory function compared to patients who have a laparotomy $[11,18]$.

According to our model, if patients have a predicted probability higher than $1.96 \%$, they are at higher risk of primary PPC and, therefore, may warrant greater attention and focus on prehabilitation. Several other studies have devised models for PPC but have covered multi-specialty procedures or multiple disease processes [19-29]. Others focused on a single adverse outcome [19-25]. Furthermore, our uniqueness is different given the fact we excluded the potential main complications after surgery that might predispose to the PPC [2]; our focus was on primary PPC. The predictive potential of our model is high, easy to use, and particularly useful for a colorectal surgical team in pre-operative planning for colorectal cancer.

One of the most significant predictive factors in the score, aside from advancing age and dependence, was a history of severe COPD (OR 3.12, 95\% CI 2.53-3.85). COPD is associated with higher rates of in-hospital complications, ICU admission, antibiotic treatment, reintervention, and mortality after colorectal cancer surgery [30]. Although MIS is associated with improved outcomes in patients with COPD [11], perioperative teams still often avoid MIS for fear of worse respiratory outcomes. This study included some 2235 patients with COPD and our score could also be applied to this cohort. In doing so, it may also help clinicians confidently engage in MIS for this subset of patients.

The model is limited having been devised from a retrospective database. The use of a database, such as NSQIP, in itself is limited by the quality of the data. Coding errors can occur for example. However, our model was internally validated using a second dataset from 2018, and predictive performance was closely approximated.

Our methods successfully built an internally validated model to predict postoperative respiratory complications, with good discrimination. Established postoperative pathways, such as 'Enhanced Recovery', have significantly reduced PPC [31], in part due to early mobilization, prevention of fluid overload, and avoidance of nasogastric tubes which minimize the risk of bronchoaspiration [32]. Our predictive model could be used to identify at-risk patients to increase postoperative resource allocation to ensure adherence to such pathways and provide pulmonary rehabilitation. Furthermore, the score can be used to guide prehabilitation and inform consent in high-risk patients.

In summary, our study identified a low rate of pulmonary complications after minimally invasive colon and rectal cancer surgery. The predictive tool may help to mitigate risk through enhancement of preventive measures.

Funding This research did not receive any funding.

\section{Compliance with ethical standards}

Conflict of interest The authors have no conflict of interst.

Ethical approval Institutional Review Board approval was not required for this study.

Research involving human participants and/or animals This article does not contain any experimental studies with human participants or animals performed by any of the authors.

Informed consent For this study, formal consent is not required.

\section{References}

1. Jurt J, Hubner M, Pache B, Hahnloser D, Demartines N, Grass F (2018) Respiratory complications after colorectal surgery: avoidable or fate? World J Surg 42(9):2708-2714. https://doi. org/10.1007/s00268-018-4699-2

2. Miskovic A, Lumb AB (2017) Postoperative pulmonary complications. Br J Anaesth 118(3):317-334. https://doi.org/10.1093/bja/ aex002

3. Haines KJ, Skinner EH, Berney S (2013) Association of postoperative pulmonary complications with delayed mobilisation following major abdominal surgery: an observational cohort study. Physiotherapy 99(2):119-125. https://doi.org/10.1016/j.physi o.2012.05.013

4. Zogg CK, Najjar P, Diaz AJ, Zogg DL, Tsai TC, Rose JA Jr, Scott JW, Gani F, Alshaikh H, Canner JK, Schneider EB, Goldberg JE, Haider AH (2016) Rethinking priorities: cost of complications after elective colectomy. Ann Surg 264(2):312-322. https://doi. org/10.1097/sla.0000000000001511

5. Rauh R, Hemmerling TM, Rist M, Jacobi KE (2001) Influence of pneumoperitoneum and patient positioning on respiratory system compliance. J Clin Anesth 13(5):361-365. https://doi. org/10.1016/s0952-8180(01)00286-0

6. O'Malley C, Cunningham AJ (2001) Physiologic changes during laparoscopy. Anesthesiol Clin N Am 19(1):1-19. https://doi. org/10.1016/s0889-8537(05)70208-x

7. Milone M, Elmore U, Vignali A, Mellano A, Gennarelli N, Manigrasso M, Milone F, De Palma GD, Muratore A, Rosati R (2017) Pulmonary complications after surgery for rectal cancer in elderly patients: evaluation of laparoscopic versus open approach from a multicenter study on 477 consecutive cases. Gastroenterol Res Pract 2017:5893890. https://doi.org/10.1155/2017/5893890

8. Li Y, Wang S, Gao S, Yang C, Yang W, Guo S (2016) Laparoscopic colorectal resection versus open colorectal resection in octogenarians: a systematic review and meta-analysis of safety and efficacy. Tech Coloproctol 20(3):153-162. https://doi. org/10.1007/s10151-015-1419-x

9. Abd El Aziz MA, Grass F, Behm KT, Shawki S, D’Angelo AL, Mathis KL, Larson DW (2020) Trends of complications and innovative techniques' utilization for colectomies in the United States. Updates Surg. https://doi.org/10.1007/s13304-020-00862-y

10. Abd El Aziz MA, Grass F, Perry W, Behm KT, Shawki SF, Larson DW, Mathis KL (2020) Colectomy for patients with super obesity: 
current practice and surgical morbidity in the United States. Surg Obes Relat Dis. https://doi.org/10.1016/j.soard.2020.06.033

11. Sujatha-Bhaskar S, Alizadeh RF, Inaba CS, Koh CY, Jafari MD, Mills SD, Carmichael JC, Stamos MJ, Pigazzi A (2018) Respiratory complications after colonic procedures in chronic obstructive pulmonary disease: does laparoscopy offer a benefit? Surg Endosc 32(3):1280-1285. https://doi.org/10.1007/s00464-017-5805-5

12. Antoniou SA, Antoniou GA, Koch OO, Kohler G, Pointner R, Granderath FA (2015) Laparoscopic versus open obesity surgery: a meta-analysis of pulmonary complications. Dig Surg 32(2):98107. https://doi.org/10.1159/000371749

13. Lee CZ, Kao LT, Lin HC, Wei PL (2015) Comparison of clinical outcome between laparoscopic and open right hemicolectomy: a nationwide study. World J Surg Oncol 13:250. https://doi. org/10.1186/s12957-015-0666-7

14. Bablekos GD, Michaelides SA, Analitis A, Charalabopoulos KA (2014) Effects of laparoscopic cholecystectomy on lung function: a systematic review. World J Gastroenterol 20(46):17603-17617. https://doi.org/10.3748/wjg.v20.i46.17603

15. Jiang L, Yang KH, Guan QL, Cao N, Chen Y, Zhao P, Chen YL, Yao L (2013) Laparoscopy-assisted gastrectomy versus open gastrectomy for resectable gastric cancer: an update meta-analysis based on randomized controlled trials. Surg Endosc 27(7):24662480. https://doi.org/10.1007/s00464-012-2758-6

16. Schiphorst AH, Verweij NM, Pronk A, Borel Rinkes IH, Hamaker ME (2015) Non-surgical complications after laparoscopic and open surgery for colorectal cancer-a systematic review of randomised controlled trials. Eur J Surg Oncol 41(9):1118-1127. https://doi.org/10.1016/j.ejso.2015.04.007

17. Hall JC, Tarala RA, Hall JL, Mander J (1991) A multivariate analysis of the risk of pulmonary complications after laparotomy. Chest 99(4):923-927. https://doi.org/10.1378/chest.99.4.923

18. Kapoor A, Nassir A, Chew B, Gillis A, Luke P, Whelan P (2004) Comparison of laparoscopic radical renal surgery in morbidly obese and non-obese patients. J Endourol 18(7):657-660. https ://doi.org/10.1089/end.2004.18.657

19. Gupta H, Gupta PK, Schuller D, Fang X, Miller WJ, Modrykamien A, Wichman TO, Morrow LE (2013) Development and validation of a risk calculator for predicting postoperative pneumonia. Mayo Clin Proc 88(11):1241-1249. https://doi.org/10.1016/j. mayocp.2013.06.027

20. Arozullah AM, Daley J, Henderson WG, Khuri SF (2000) Multifactorial risk index for predicting postoperative respiratory failure in men after major noncardiac surgery. The National Veterans Administration Surgical Quality Improvement Program. Ann Surg 232(2):242-253. https://doi.org/10.1097/00000658-20000 $8000-00015$

21. Gupta H, Gupta PK, Fang X, Miller WJ, Cemaj S, Forse RA, Morrow LE (2011) Development and validation of a risk calculator predicting postoperative respiratory failure. Chest 140(5):12071215. https://doi.org/10.1378/chest.11-0466

22. Canet J, Sabate S, Mazo V, Gallart L, de Abreu MG, Belda J, Langeron O, Hoeft A, Pelosi P (2015) Development and validation of a score to predict postoperative respiratory failure in a multicentre European cohort: a prospective, observational study. Eur J Anaesthesiol 32(7):458-470. https://doi.org/10.1097/eja.00000 00000000223
23. Hua M, Brady JE, Li G (2012) A scoring system to predict unplanned intubation in patients having undergone major surgical procedures. Anesth Analg 115(1):88-94. https://doi.org/10.1213/ ANE.0b013e318257012b

24. Blum JM, Stentz MJ, Dechert R, Jewell E, Engoren M, Rosenberg AL, Park PK (2013) Preoperative and intraoperative predictors of postoperative acute respiratory distress syndrome in a general surgical population. Anesthesiology 118(1):19-29. https://doi. org/10.1097/ALN.0b013e3182794975

25. Kor DJ, Warner DO, Alsara A, Fernandez-Perez ER, Malinchoc M, Kashyap R, Li G, Gajic O (2011) Derivation and diagnostic accuracy of the surgical lung injury prediction model. Anesthesiology 115(1):117-128. https://doi.org/10.1097/ALN.0b013e3182 1 b5839

26. Jeong BH, Shin B, Eom JS, Yoo H, Song W, Han S, Lee KJ, Jeon K, Um SW, Koh WJ, Suh GY, Chung MP, Kim H, Kwon OJ, Woo S, Park HY (2014) Development of a prediction rule for estimating postoperative pulmonary complications. PLoS ONE 9(12):e113656. https://doi.org/10.1371/journal.pone.0113656

27. Wong DH, Weber EC, Schell MJ, Wong AB, Anderson CT, Barker SJ (1995) Factors associated with postoperative pulmonary complications in patients with severe chronic obstructive pulmonary disease. Anesth Analg 80(2):276-284. https://doi. org/10.1097/00000539-199502000-00013

28. Canet J, Gallart L, Gomar C, Paluzie G, Valles J, Castillo J, Sabate S, Mazo V, Briones Z, Sanchis J (2010) Prediction of postoperative pulmonary complications in a population-based surgical cohort. Anesthesiology 113(6):1338-1350. https://doi. org/10.1097/ALN.0b013e3181fc6e0a

29. Mazo V, Sabate S, Canet J, Gallart L, de Abreu MG, Belda J, Langeron O, Hoeft A, Pelosi P (2014) Prospective external validation of a predictive score for postoperative pulmonary complications. Anesthesiology 121(2):219-231. https://doi.org/10.1097/ aln.0000000000000334

30. Bare M, Monton C, Mora L, Redondo M, Pont M, Escobar A, Sarasqueta C, Fernandez de Larrea N, Briones E, Quintana JM (2017) COPD is a clear risk factor for increased use of resources and adverse outcomes in patients undergoing intervention for colorectal cancer: a nationwide study in Spain. Int J Chronic Obstr Pulmon Dis 12:1233-1241. https://doi.org/10.2147/copd.S130377

31. Greco M, Capretti G, Beretta L, Gemma M, Pecorelli N, Braga M (2014) Enhanced recovery program in colorectal surgery: a meta-analysis of randomized controlled trials. World J Surg 38(6):1531-1541. https://doi.org/10.1007/s00268-013-2416-8

32. Gustafsson UO, Scott MJ, Schwenk W, Demartines N, Roulin D, Francis N, McNaught CE, Macfie J, Liberman AS, Soop M, Hill A, Kennedy RH, Lobo DN, Fearon K, Ljungqvist O (2013) Guidelines for perioperative care in elective colonic surgery: Enhanced Recovery After Surgery (ERAS((R))) Society recommendations. World J Surg 37(2):259-284. https://doi.org/10.1007/ s00268-012-1772-0

Publisher's Note Springer Nature remains neutral with regard to jurisdictional claims in published maps and institutional affiliations. 